\title{
CAPACITY UTILIZATION ANALYSIS OF HPLC INSTRUMENTS FROM THE ASPECT OF HUNGARIAN FOR- AND NON-PROFIT SECTOR
}

\author{
Anita Tolnay, András Koris, Nándor Komáromi, Szergej Vinogradov \\ Szent Istvan University, Hungary
}

\begin{abstract}
This study focuses on the development of a method in order to measure and evaluate the capacity utilization of forty laboratory instruments in the analytical field of chromatography in the two major sectors, namely non-profit and for-profit. The procurement of the laboratory instruments was either from own institution's budget or European Union projects funded. The primary objective of this survey is to identify appropriate laboratory capacity utilization and productivity measures and analyze the potential cost benefit. The measurements were carried out by idle-time indicators for a 12-months/ a year period of time to determine the efficient utilization of the laboratory devices. The analyzed data were gathered from the Hungarian laboratory market as an own research. The significant difference was found between the classifications and periods of idle times for an HPLC instrument for non-profit and profit-oriented institutes and thus capacity utilization is slightly different in these two cases. Based on the results, at last it was stated that a number of effect of EU resources on R\&D development and their significance is still unsolved and so a more complex survey has to be carried out in future in the major sectors of the laboratory B2B market. In this work only the most important aspects based on the Research and Development activities were examined for sustainable economic development. Naturally, the conceptual scope and extent of this study do not permit all the possible issues to be examined from every aspect, thus it will be endeavored to point out merely the most relevant considerations.

KEY WORDS: analytical instruments; capacity utilization; laboratory market; research and development.
\end{abstract}

\section{Introduction}

There is no doubt that $\mathrm{R} \& \mathrm{D}$, through innovation as well as technological developments, plays the key role in globalization, sustainable development and turbulent competitiveness. R\&D spending, Gross Domestic Expenditure on R\&D (GERD) is one of the main Europe 2020 strategy indicators, the ratio of GERD to GDP also known as R\&D intensity, which constitutes the source of long run endogenous economic growths. The level of GERD has been increasing modestly since 2006 within the range of $1.76 \%-2.04 \%$ in EU-28 Member States, set back by the financial and economic crisis (2008-2009) led to deep cuts in funding for scientific research (Nature Cell Biology 2012). R\&D expenditure is being identified by the share of the performance within the four main sectors, such as business enterprise sector, higher education sector, government sector and private nonprofit sector. The performance of the EU Member States differs significantly, especially concerning the 15Member States and the New Members joining the EU after 2004.

Grablowitz et al. (2007) attempted to analyze R\&D expenditure, researcher numbers, related policy and its instruments applied to foster private $R \& D$ as well as the financial support from government is given to business R\&D to find R\&D trends in Europe. Their study revealed that only three out of the fifteen sectors, namely 'motor vehicle', 'pharmaceuticals' and 'computer and related activities' showed significant increase in both numbers of researchers and expenditures over the surveyed decade.

According to Petrariu et al. (2013) the development level of a country is the engine of innovation, allocating funds to R\&D is the main source of support offered in this respect. Welfare, - seen with the help of the human development index, - has a key role in enhancing the innovation in a country. However, innovation is still in a catch-up phrase, related to the growth rate in the CEE countries as Petrariu et al. (2013) reveal in their study.

The subject matter of this paper is the analysis of the private and public Research and Development (R\&D) spending on innovation, through the measurement of research in laboratory field, based on the impact of science for optimizing laboratory operations through capacity utilization (CU) factors based on a 12-monthtimescale of laboratory instruments' operation in the two main sectors, namely non-profit (NP, e.g. university-, academic laboratories) and for-profit (FP, e.g. private research- or contract laboratory). The laboratory equipments' investment either based on the laboratories' own budget procurement or financially supported by European Union Operative Program Funds. Our main interest is in the measurement of the contribution of efficiently and optimally utilized capacity as well as identifying the unused capacity along with measures of technical inefficiency and other time-scale factors defining the potential spare capacity in the operation of a certain analytical High-Pressure Liquid Chromatography (HPLC) instruments. The principal aims of this paper besides surveying the optimal capacity utilization in the Hungarian laboratory segment, also to insure new methods to be proposed providing practical advice to lab managers for monitoring their asset utilization in order to achieve better performance in the future.

There have been no prior attempts to examine this scientific research field previously, hence no scientific literatures or publications are to be found from this approach. So the current study is trying to fulfill the basic aspects of this 'gap' by providing a deeper understanding the sectorial differences (non-profit and for-profit) of laboratory research performance as well as identifying the 
obstacles to be hindered in order to achieve sustainable economic growth in the long-run R\&D activities.

This study is divided in three parts. The first section gives a general overview on the European R\&D trends, outlines the Lisbon strategy (2000) rested on a number of pillars, which included preparing the transition towards a knowledge based economy by the creation of an European Research Area (ERA), as well as the Strategy of Europe 2020, the strategic guidelines towards sustainable and inclusive growth (Albu 2011). The next section provides a definition of capacity as well as introduces various perspectives of theoretical and empirical capacity utilization models with help of scientific literatures. In the last part our primer research will be introduced on the scientific laboratory instruments' niche market.

\section{Theoretical background and literature review}

\section{European Union Research and Development trends}

The challenges of a new knowledge-driven economy as well as globalization required radical transformations of the European economy set by the Lisbon Strategy in 2000. The aim of the Lisbon Strategy, launched in March 2000 by the EU heads of state and government, was to make Europe, as the new strategy goal, "the most competitive dynamic knowledge-based economy in the world, capable of sustainable economic growth with more and better jobs and greater social cohesion" (European Committee of the Regions 2000). At the early stage of 2000 , the whole concept was built on two different pillars, namely economic and social, while environmental dimension, as the third pillar came into the picture a bit later. Besides the strengths in the European Union, there are certain areas with weaknesses, where overall strategy is needed to overcome, aiming at ,transition to a knowledge-based economy and society by better policies for the information society and $\mathrm{R} \& \mathrm{D}$, as well as by stepping up the process of structural reform for competitiveness and innovation and by completing the internal market" (Lisbon European Council 2000). R\&D funding is one of the major instruments for steering the science system. Given the significant role played by research and development in generating economic growth, the main objective is to set all opportunities "Towards a European Research Area". In line with that, the European Council defined the objective of $3 \%$ of GDP allocated to R\&D spending in 2002 with more focus on economic growth, using guidelines laid out in the Frascati manual, published by the OECD.

In analogy to this, the European Union's latest growth strategy, Europe 2020 strategy, sets the target of 'improving the conditions for innovation, research and development', called 'An European strategy for smart, sustainable and inclusive growth', in particular with the aim of 'increasing combined public and private investment in R\&D to 3\% of GDP' by 2020 , in order to provide a stimulus EU competitiveness. According to the European statistics R\&D intensity in the EU is growing too slowly to meet the Europe 2020 target. As shown in Figure 1, the EU's R\&D expenditure surpassed $2 \%$ of GDP in 2013, and has more or less stagnated close to this level since then. The EU has therefore not seen a strong move towards its 3\% R\&D intensity target for 2020 over the past few years, making its achievement more and more unlikely.

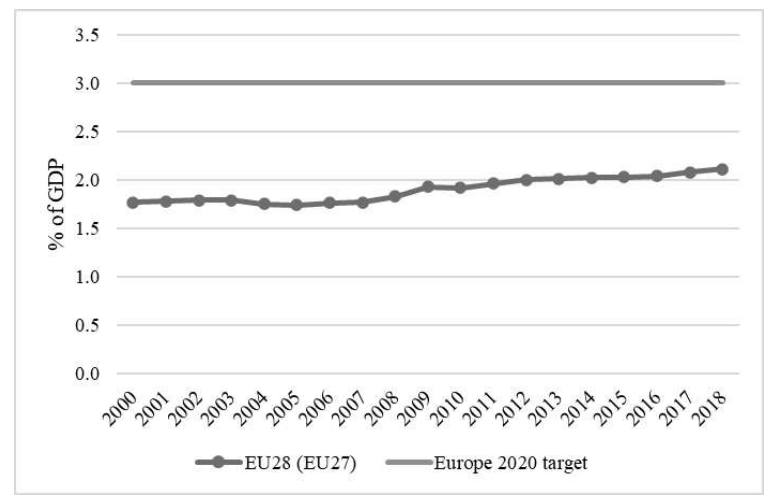

Fig. 1. Gross domestic expenditure on R\&D (GERD) $\%$ of GDP

\section{Source: the authors' edition based on the data of Eurostat 2020}

R\&D activities are performed by four main institutional sectors: business enterprise, government, higher education and the private non-profit sector. The distribution of $R \& D$ expenditure between these four sectors in 2008 and 2017 can be seen at Figure 2. In 2017, the biggest investor is the business enterprise sector, strengthening its position with spending EUR 209.2 billion on R\&D, accounting for about two-thirds of the EU's total R\&D expenditure. It has also been responsible for the slight increases in the EU's total R\&D intensity since 2012. Meanwhile, the public sector (higher education and government sectors) does have an important role to play in R\&D expenditure, amounted to only about a third of total R\&D expenditure in the EU in the same year.

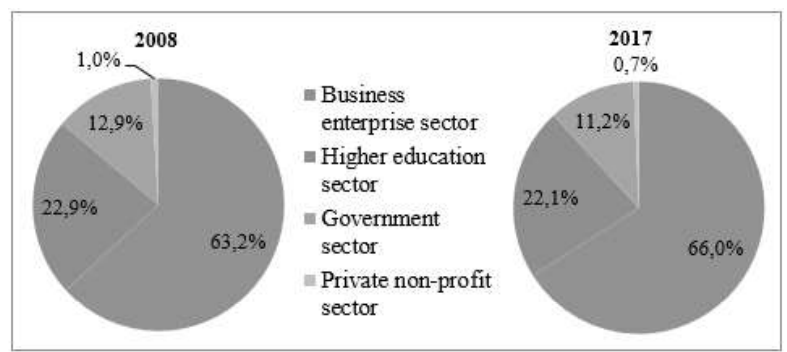

Fig. 2. R\&D expenditure by sectors of performance in the EU28, in 2008 and 2017

\section{Source: the authors' edition based on the data of Eurostat 2020}

Out of the four R\&D performing sectors, only the two major ones (business enterprise and higher education) have increased their R\&D intensities since 2008 (Fig. 4), while the other sectors stagnated or saw slight declines (Eurostat Statistic Explained 2020).

An empirical analysis of 2018 working with the database of Eurostat, based on the actual spending on $R \& D$ by the main sectors, the majority of $R \& D$ expenditure was generated in the business enterprise sector, where the expenditure rose from $1.12 \%$ of GDP in 
2006 to $1.32 \%$ by 2016 . Followed by the higher education, reaching $0.47 \%$ of GDP. While the other two remaining sectors, the government sector $(0.23 \%$ of GDP), and the private non-profit sector $(0.02 \%$ of GDP) changed slightly throughout the examined period. In 2011, The 7th framework program, announcing Horizon 2020, for investing almost EUR 80 billion in research and innovation, was presented by the European Commission (Eurostat statistics 2018 March).

In Hungary, grants paid from EU Structural Funds related to the 'Science and Innovation Program' of the New Széchenyi Plan, co-financing innovation activities was EUR 680 million over the period of 2010 to 2013. One of the most important components of innovationspecific EU-funds supports higher education institutions' research and research infrastructure development expenditures (Prauliņš 2013).

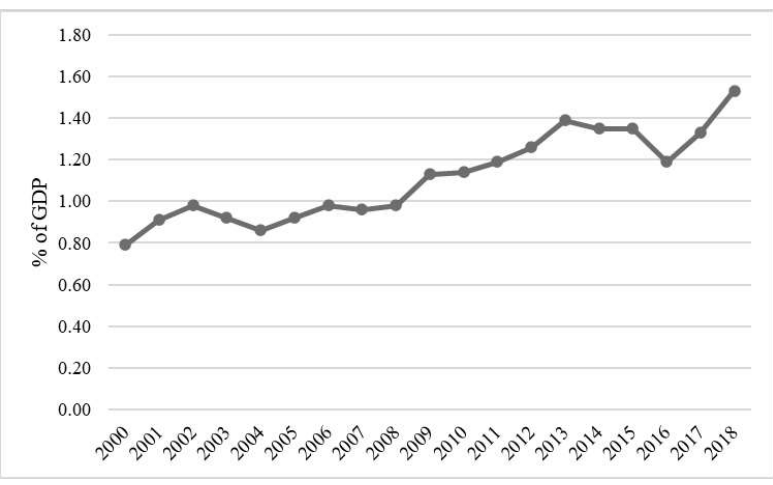

Fig. 3. Research and development (R\&D) expenditure as a percentage of GDP in Hungary, 2000-2018

Source: the authors' edition based on the data of Eurostat 2020

Figure 2. indicates that the amount of support allocated to foster research, development and innovation activities have considerably increased over the surveyed period of 2000 to 2018. Performance by the main input indicator of GERD, definitely started to converge to those of established EU economies (Szalavetz 2014).

\section{Capacity utilization measurement}

In simple terms, capacity may be defined as the ability of a firm or industry to produce a potential output' (Vestergaard, 2003). According to Corrado, Mattey (2016) capacity utilization is a ratio of the actual level of output to a sustainable maximum level of output, or capacity. Capacity utilization involves a set of related microeconomic issues (Corrado, Mattey 2016; Gružauskas et al. 2016). Summers (1996) defines capacity utilization as the percentage of the firm's total possible production capacity that is being used, which can be measured in two ways, either by the estimated goal function or using Wharton measure that investigates the microeconomic implications capacity utilization (Sarbapriya 2013). The capacity index is designed to embody the concept of sustainable practical capacity, defined as the greatest level of output each plant in a given industry, taking account of normal downtime and assuming sufficient availability of inputs to operate machinery and equipments in place.

Many alternative CU measures have been defined, but there is no generally accepted way of defining measuring CU. According to the scientific literature, measures of capacity utilization $(\mathrm{CU})$ have been used for many years to analyze the current 'state' of economy and contractionary forces that might exist (Segerson 1988).

An early-stage, but very effective definition of a firm's capacity output, is defined by Cassel (1937) is the production level at which long-run average cost curve reaches its minimum (Ray, Mukherjee, Wu 2005).

In several economics literatures capacity measurements are divided into two main groups by its definition, namely 'Physical definitions of capacity' by Gold in 1955, utilizing purely the concept of the production function, which was further labeled by Johansen 13 years later in 1968, merely for a single output technology, determining the maximum producible amount of unit in time. More economically meaningful measures of capacity of the recent decades, namely the 'Economic definition of capacity', was closely tied to the economic theory of firm behavior (Coelli, Grifell-Tatje, Perelman 2000). Pioneering studies in this area include the research by Klein (1960) and Hickman (1964) and Morrisons (1985) as well as Berndt and Fuss (1986) have defined CU using the concept of the firm's short-run cost function where one or more inputs are being treated as quasi-fixed. Optimal capacity for the suggested output level by Klein (1960) was the point at which the short-run (SCAR) and long-run average cost (LRAC) function were at a tangency (Coelli, Grifell-Tatje, Perelman 2000).

In accordance with the classification of the above measurements, another approach of two distinct measures of capacity, a technical-economic measure and a strictly economic measure (Morrison, 1985). The technologicaleconomic measure is a concept of capacity offered by Johansen (1968, p. 68) defined capacity as '....the maximum amount of that can be produced per unit of time with existing plant or equipment, provided the availability of variable factors of production is not restricted. According to Prior and Filimon, one of the most used definitions of CU rate is as the ratio of actual output to the potential output. The output can be defined by either technical approach to which potential output represent the maximum amount of output, produced in a short-run (Vestergaard-Squires-Kirkley, 2003). Contradiction to technological capacity measurement, pure economic measure defines the capacity output as being consistent with the output level that optimizes the behavioral objective of a firm (Vestergraad 2003). While Klein and Long (1973, p. 744) states that 'Full capacity should be defined as an attainable level of output that can be reached under normal input conditions-without lengthening accepted working weeks, allowing for usual vacations and for normal maintenance.'

There have been several capacity utilization models and cost measurements taking different approach to measuring the utilization and cost of capacity. These models are grouped according to the capacity measures: 
- Theoretical capacity: the optimal amount of work, which can be completed in 24-hour with zero waste.

- Practical capacity: theoretical capacity minus unavoidable nonproductive time (instrument set up, maintenance, breakdowns).

- Normal capacity: the average utilized capacity of a lab device.

There is another important factor to deliberate in the issue of time frame of analysis when capacity utilization is being measured. The function of time for capacity utilization divided into three main categories: idle capacity; nonproductive capacity; productive capacity. Haupt highlighted in his thesis work in 1998, that these categories added together will give the total rated capacity of an equipment usage.

The CU measurement differs from the industrial sectoral features, thus the choice of the $\mathrm{CU}$ model requires careful consideration during the decision making process.

Bitange Nyaoga et al. (2015) study approached capacity utilization from the aspects of Theory of Constraints (TOC) and sought to determine the relationship between constraints management and capacity utilization. It is also called the as problemsolving methodologies. The TOC thinking processes emphasizes on the factors that are limiting the system from achieving its goals. Goldratt (1990) reveals that it is the weakest link that limits the overall performance of an organization, also it must identify the system's constraints or bottleneck. Companies that operate at full capacity face challenges like lack of time for routine maintenance, machine breakdown frequently occur, delayed orders, demotivated staff, inefficient work, increasing labor costs (Summers 1996, Sarbapriya 2013), which badly effect competitiveness.

\section{Methodology of research}

\section{Data collection}

Data was collected from primary sources in the laboratory instrumentation field. The analysis was applied to only a single year included 40 laboratories, examining the same type of specific laboratory instrument, namely the High-Pressure Liquid Chromatography (HPLC) instrument purchased. The survey took place in the winter of 2020, in January and February. Thus, the measure of capacity is merely conditional and data resource prevailed in year 2019. The survey, due to the sensitive nature of area of investigation, was conducted with a relatively low level of sample attainable at this stage, owing to the small size of the segment and its intensive market specificity as well as confidentiality. The study was an extended version of an early stage research of the summer of 2018, where due to the shortness of the research time, only 4 laboratories, 2-2 from FP and NP sectors were examined. The currently analyzed data were gathered from 20 laboratories (a university and an academic one) from the non-profit sector (NP) and 20 private laboratories from the for-profit sector (FP) in the laboratory market. Selfadministered, structured questionnaire (Annex 1.) was the primary tool for collecting primary data. Authors contacted personally all respondents prior to the questionnaire survey to assure laboratory managers of confidentiality as well as explaining the purpose of the study. Furthermore, interviews had been carried out with laboratory managers to determine the productive and nonproductive operation of the lab instruments as an own research. The interviewed laboratories performed tasks at different fields of activities. Half of the NP laboratories were universities' labs in the field of education and research, while $30 \%$ was from the academic field and the remaining $20 \%$ was from governmental labs, such as NÉBIH, NAIK, etc. Over $60 \%$ of the FP laboratories were pharmaceuticals and the remaining $40 \%$ was either smaller private labs or contract labs supporting production technology or customer service for external measurement and sponsor funded projects.

Data analysis

Bitange Nyaoga et al. (2015) computed the capacity utilization for individual outcome measures of actual outcome and design capacity for each year.

$$
\mathrm{CPMFt}=\frac{\text { Actual output }}{\text { Design capacity }}
$$

where CPMFt is the capacity utilization for each firm, Actual output is the rate of production achieved which cannot exceed the effective capacity, Design capacity is the maximum output rate or service capacity of operation process.

Similar equation model was introduced as the Capacity Utilization Index (CUI or $\eta$ ) in the work of Bóna et al. (2012) for the industrial production is calculated with the following equation:

$$
\eta=\frac{\mathrm{N}_{\mathrm{kh}}}{\mathrm{N}} \cdot 100(\%)
$$

where $\mathrm{Nkh}$ is the realistic throughput (number of products produced), $\mathrm{N}$ is the theoretical (maximal) throughput (in pieces).

The above shown CUI equation is developed for production on produced amount/hour basis but research and development is not a production type of activity. It is nearly impossible to define the measure of output and furthermore it is not constant in each case. In the success of CU measurement for laboratory facilities it is critical to determine significant factors for indicators.

Due to the sector specification - it is hard to express the $\mathrm{CU}$ in the amount of products in a certain time (e.g. pcs/hour) - the Authors defined a modified equation in time frame (hour/year), including operation hours and time loss for the instruments (Eq. 3.) based on the concept of (Eq. 1.) and (Eq.2.).

$$
\mathrm{CUI}_{\text {lab }}=\frac{\mathrm{T}_{\text {productive }}}{\mathrm{T}_{\text {total }}} \cdot 100(\%)
$$

Where $\mathrm{CUI}_{\text {lab }}$ is the capacity utilization index for an analytical laboratory instrument, $\mathrm{T}_{\text {total }}$ is the theoretical maximal annual working hours for the given instrument, $\mathrm{T}_{\text {productive }}$ is for the practical measurement hours per year.

The time frame of analysis is an important factor in the laboratory segment, where R\&D laboratories perform several different projects, which are cyclical and have no standard duration. Therefore, the measure of $\mathrm{CU}$ for instrument is using time, so the modified equation 
implemented in this study can be used for comparing to similar laboratories and lab devices to be able to evaluate as one indicator of overall capacity utilization.

\section{Research hypotheses}

The survey analyze the capacity utilization differences between the two main sectors, NP and FP. Based on the study objectives and literature review, the following hypothesizes were tested:

H1: The approximate time (minutes) for one measurement is the same in both, NP and FP sectors.

$\mathrm{H} 2$ : The unproductive time (hours) is higher in NP sector than in FP sector in terms of operation.

H3: There is a difference between NP and FP sectors' capacity utilization in favor of FP.

\section{Results and Discussion}

Descriptive statistics was carried out on the collected data related to measurement time, unproductive time and capacity utilization. Furthermore, two-sample t-test was also performed on the measurement time in the main sectors. The overall results of the survey can be interpreted from two different aspects: on the one hand, the difference in capacity utilization (CU) of the laboratory instruments, HPLC either in the frame of EU funded project or on the basis of own budget procurement between the two main sectors; on the other hand, the discrepancy due to the nature of their research-driven activities within each sector's CU's results, such as university or academic basic research vs. private lab's own applied research or contract lab's outsourced external measuring orders. The measurement results were merely focusing on a 12-month-period of time in 2019 with evaluation of time efficiency calculation for each examined projects.

According to the questionnaire answers average annual working days have shown wide variance from 100 up till 350, owing to instrument utilization in the lab, with a dispersion of around 163 for NP average and 256 for FP average. The result might be due to a clear difference as for-profit is an academic research scene; in contrast of universities, where mostly education is the main function. The number of work shifts is almost $25 \%$ higher for FP, as contract labs work for external orders under time pressure. The above is also supported by the annual numbers of projects (orders) in the two main sectors. FP carried out 20 times more projects than NP. This can be explained as well with the difference in the organizations functionality; at a university the researchers are conducting analytical research when education allows it.

Significant differences were found in approximate time of a measure, as it can be seen in Figure 4. The measure times are naturally different, depending much on the applied method, as well as the brand and technical differences for the HPLC and the quality of its columns used, so the results were completely different due to this reason. Although the measurement time was definitely higher for NP institutes than FP organizations. It is clearly visible as well, that for-profit organizations are operating with much shorter measure times with average of 13.75 minutes. The average time for non-profit institutes were three times of the FP companies (40.5 minutes).

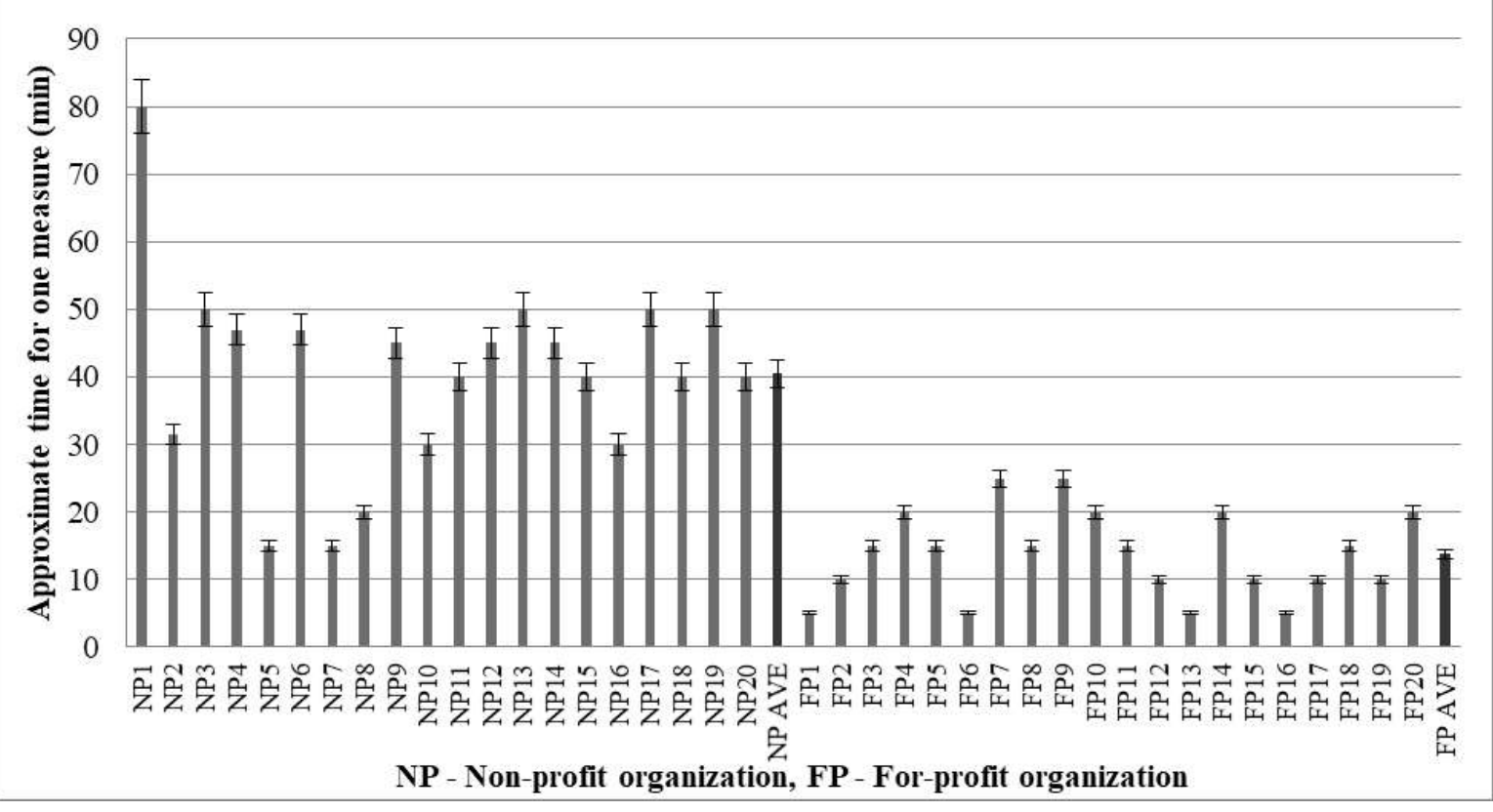

Fig. 4. Comparison of approximate time for one measure in NP and FP organizations

Source: own calculation based on own research data 
The result of the two-sample t-test $(\mathrm{t}=7.46, \mathrm{df}=38$, $\mathrm{p}<0.001$ ) shows a significant difference in the mean value of the average time of measurements between the two examined sectors. Much longer measurement time is detected in all laboratories operating in the NP sector, than in the FP.

In Figure 5. unproductive times of the chromatography instruments are introduced and compared. Very similar results were obtained compared to measure times. In case of NP organizations the unused time is quite high compared to FP's. The average time lost due to different reasons like instrument failures or lack of chemicals, in case of NP institutes was calculated for 772 hours but for FP companies only 171,8 hours, which is multiplied by four and a half times in favor of FP sector. The main reasons for the relatively high unproductive time were pointed out as well by the responders: the lack of order, the repair time of the instrument, the unfilled operator position, power outage and shortage of chemicals have caused mostly unwanted break in operation even for weeks.

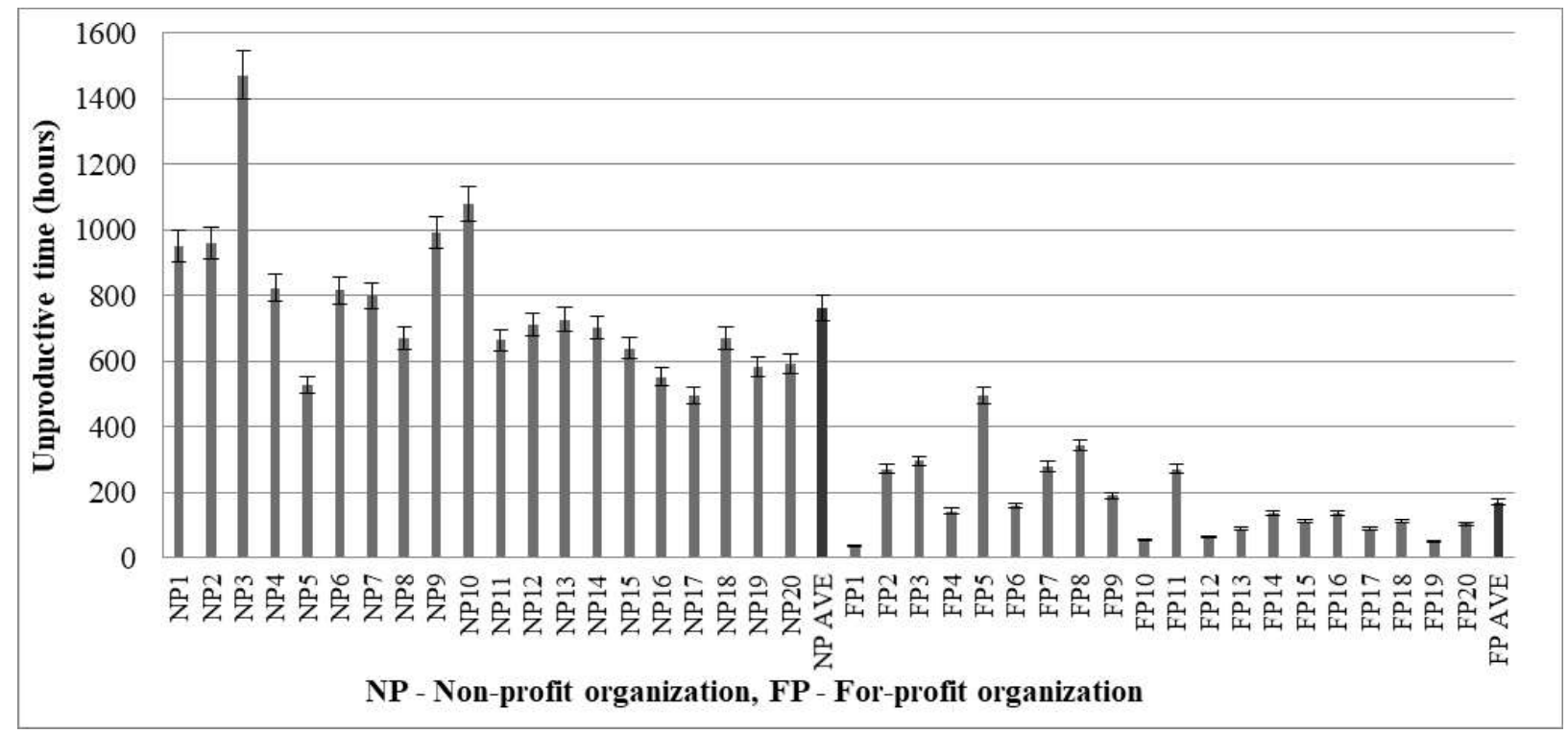

Fig. 5. Total unproductive times for the 4 organizations

Source: authors' calculation based on own research data

The result of the two-sample $\mathrm{t}$-test $(\mathrm{t}=10.309, \mathrm{df}=38$, $\mathrm{p}<0.001$ ) shows a significant difference in the mean value of the unproductive time between the two examined sectors. It can be determined that the average unproductive time for NP sector is almost four and a half time longer than for FP. According to F-probe with the result of 4,373 it can be stated that the variances are not equal, so the H2 hypothesis is accepted, 'The unproductive time (hours) is higher in NP sector than in FP sector in terms of operation'.

The CU index (CUI) were calculated for each instrument according to Eq.3. The results are represented in Figure 6. The members of the for-profit sector have proved excellent CUI with average of $91 \%$. In contrast the academic departments (NP's) average CUI was found only $42 \%$.
There is significant difference in CUI among the NP institutes and this fact highlights that there might be relatively large disparity even among the members of non-profit sector. In contrast, the CU indexes of the FP companies are very close to each other at a $90 \%$ confidence level: the lower limit of the confidence interval is $87 \%$ and the upper confidence limit equals $95 \%$.

The result of the two-sample t-test $(\mathrm{t}=-12.83, \mathrm{df}=38$, $\mathrm{p}<0.001$ ) shows a significant difference in the mean value of the CUI between the two examined sectors. Large fluctuations are observed in NP, while the value of FP's CUI can be said to be constant throughout. 


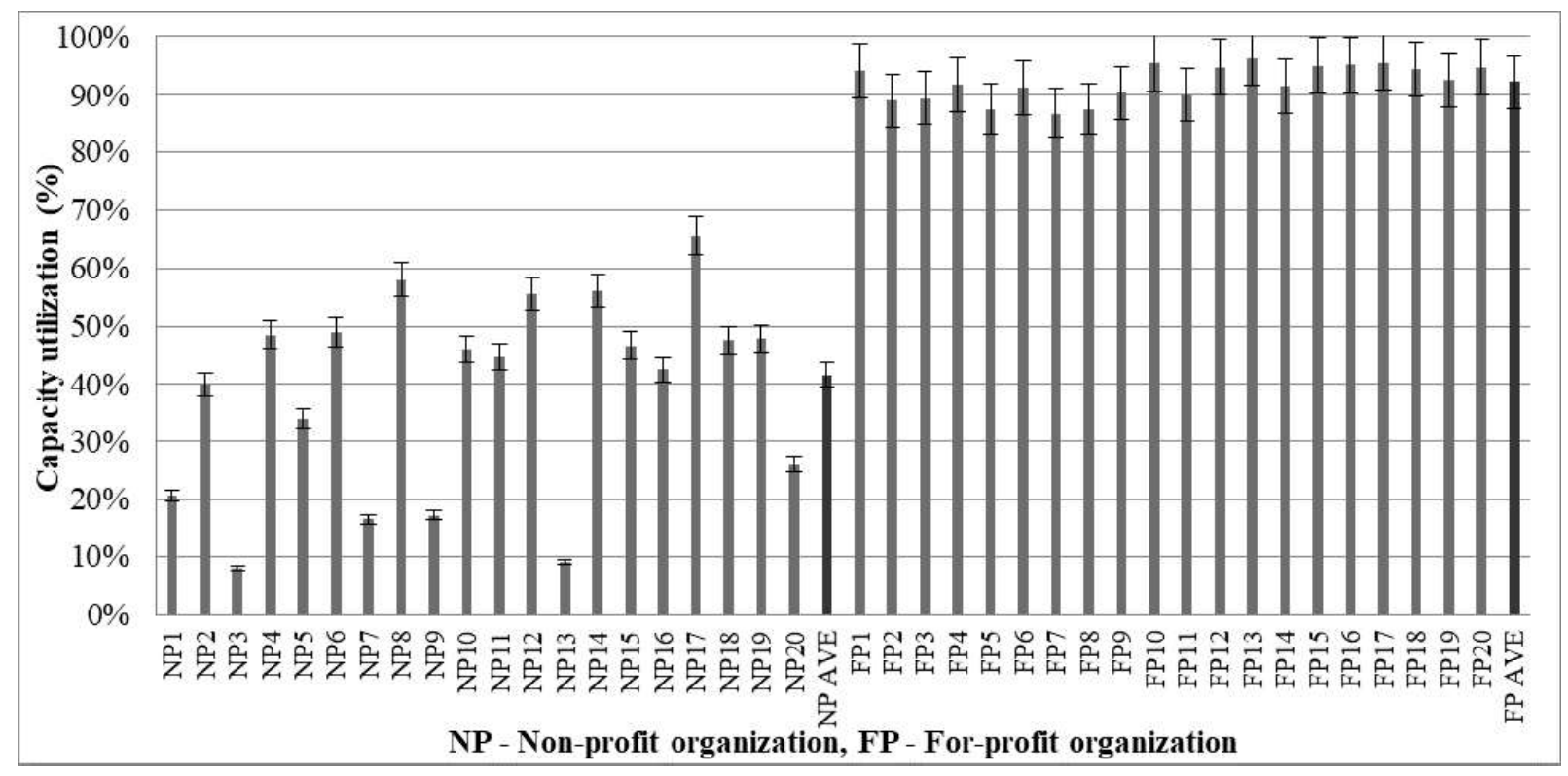

Fig. 6. Calculated capacity utilization indexes for each organization

Source: authors' calculation based on own research data

\section{Conclusion}

The importance of R\&D is becoming more and more decisive nowadays. The support of it has been increasing through instrument recruitment via proposals in the last years. This activity allows to refresh the apparatuses for different research organizations or to recruit new instruments next to existing ones. Capacity utilization of instruments opens a new path in research, as in such projects only the scientific work carried out on the new instrument is reported and controlled but the utilization, especially later in time, is not investigated. Due to insufficient governmental and private financial support even non-profit organizations, such as universities are pushed more and more to earn their budget nowadays, although most of the HPLC devices had been tender procurement in the NP sector, reveals the research. The utilization of hidden capacities of analytical instruments is a promising way to increase the income and to strengthen the position of an institute. The analytical laboratories are unfortunately much closed units and since that fact the data collection is more difficult compared e.g. to consumer technical insights (CTI's) tests). In the current study the authors attempted to gather basic data from both for- and non-profit organizations, to develop a method in order to evaluate laboratory instrument CUI and to test this modified CUI calculation method based on scientific theoretical literature as well as empirical studies. The result, according to expectations showed excellent CUI for FP companies but the utilization proved to be poor for NP university departments, which can be traced back to a number of factors. The paper has pointed out several obstacles, for example the lack of order, the repair time of the instrument, the unfilled operator position or the shortage of chemicals - mainly for NP organizations, which are seriously responsible for the low capacity utilization of a given instrument. It can be concluded that cooperation between universities and industry could help to overlap the differences in the operation within the sectors. The results presented in this work are preliminary and has to be regarded carefully mainly due to the quite difficult data collection of this confidential scientific segment as well as the low number of answers. The results can be altered by changes in these conditions or by using extended data, which our current analysis would not depict. Thus, the results carried out in this examination might not be widely indicative of laboratory capacity output levels under different data resource conditions due to the low sample ratio to be used.

The modified calculation method for analytical instrument CUI proved reasonability in the evaluation of a given instrument; however the method is in an early stage of development, it is clearly able to classify instruments based on data logging. In order to get precise result, data recording and processing has to be organized independently. Furthermore, our novel method can help to identify and bottlenecks in the analytical laboratory sector, especially recommended for non-profit sector members.

In future, this survey has to be extended to get more data and more accurate conclusions, which is one of the main targets of the authors. So far the CUI calculation method modified for analytical instruments and discussed in this paper seems applicable for the utilization analysis of a given apparatus. 


\section{References}

Albu, N. (2011). Research and Development spending in the EU: 2020 growth strategy in perspective. Working Paper $F G$ 1, 2011(08), SWP Berlin

Bóna, K., Juhász, J., Kovács, P., Kovács, G., Lénárt, B., and Tokodi, J. (2012). Plant organization (in Hungarian), Typotex Kiadó, Budapest

Coelli, T., Grifell-Tatje, E., and Perelman S. (2000). Capacity utilization and profitability: A decomposition of short run profit efficiency, CEPA, School of Economics, University of New England, North American Productivity Workshop, June 2000

Corrado, C., Mattey, J. (1997). Capacity Utilization, Journal of Economic Perspectives, Vol. 11., Number 1., 151-167.

Fratesi, U., Perucca, G. (2014). Territorial capital and the effectiveness of Cohesion Policies: an assessment for CEE regions, Investigaciones Regionales, 29, 165-191.

Goldratt, E.M. (1990). What is This Thing Called Theory of Constraints and How Should It Be Implemented? North River Press

Grablowitz, A., Delicado, A., Laget, P. (2007). Business R\&D in Europe: Trends in Expenditures, Researcher Numbers and Related Policies, JRC Scientific and Technical Reports, Erawatch, Joint Research Centre Directorate General Research, EUR 22937 EN

Gružauskas, V, Karosevičiūtè, D, Srovnalíková, P (2016). Labor and Machine efficient utilization importance to the enterprise profit, Vadyba Journal of Management, Nr. 1 (28)ISSN 1648-7974

Haupt, J. S. (1998). Thesis work: RDT\&E Laboratory Capacity Utilization and Producivity Measurement Measurement
Methods for Financial Decision-Making within DON, Naval Postgraduate School, Monterey, California

Petrariu, I.R., Bumbac, R., Ciobanu, R. (2013). Innovation: a path to competitiveness and economic growth. The case of CEE countries. Theoretical and Applied Economics, Vol. XX, No. 5(582), p. 15-26.

Prauliņš, A. (2013). Some issues in innovation policy evaluation, Management Journal of Management, No 1(22), ISSN 1648-7974

Prior, D., Filimon N. (2002). On the measurement of capacity utilization and cost efficiency: A non-parametric approach at firm level. Pesquisa Operacional, v.2, n.2, p. 247-263

Ray, S.C., Mukherjee, K., Wu, Y. (2005). Direct and Indirect measures of capacity utilization: A Nonparametric Analysis of U.S. Manufacturing; Uconn Libary Economics Working Papers, 200536

Sarbapriya, R. (2013). A Close Look into Research Studies on Capacity India and Abroad, Int. J. Econ. Financ. Manag., vol. 2. no. 1. p. 52-59.

Segerson, K; Squires, D. (1990). On the measurement of economic capacity utilization for multi-product industries, Elsevier Science Publisher B.V.

Summers, K. (1996). The Wharton Index of capacity Utilization Studies

Szalavetz, A. (2014). Innovation in Hungary - The Impact of EU Accession and Integration into Global Value Chains, Institute of World Economics, MTA KRTK, Hungarian Academy of Sciences, International Journal of Management and Economics, No. 42. April- June 2014, pp. 40-59

Vestergaard, N., Squires, D., and Kirkley, J. (2003). Measuring capacity and capacity utilization in fisheries; Elsevier Science, Fisheries Research 60.

RECEIVED: 15 October 2020

\section{ACCEPTED: 1 December 2020}

Anita Tolnay, PhD Candidate, Doctoral School of Management and Business Administration in Szent István University (Hungary). Research area: laboratory market. E-mail: tolnay.anita@labex.hu

András Koris, $\mathrm{PhD}$ (in food sciences), Associate Professor in Szent István University (Hungary), Faculty of Food Science. Research area: Oils, whey, static mixing and ultrafiltration, membrane emulsification, microencapsulation, vacuum drying, process modeling, soybean peptide production, particle characterisation. E-mail: Koris.Andras@szie.hu

Nándor Komáromi, PhD (in economics), Associate Professor in Szent István University (Hungary), Faculty of Economic and Social Sciences. Research area: application and development of quantitative methods in marketing management Relationship between marketing management and logistics (marketing-logistics).

Sergey A. Vinogradov, PhD (in business and management), Associate Professor in Szent István University (Hungary), Faculty of Economic and Social Sciences, Institute of Economics and Methodology. Head of the Department of Methodology. Current research area: social economical statistics, actual problems of sustainable development in EU countries. E-mail: Vinogradov.Szergej@szie.hu 
Technology sciences, Capacity Utilization Analysis of HPLC Instruments from the Aspect of Hungarian for- and NonProfit Sector

\section{Annex 1.}

\section{QUESTIONNAIRE}

Survey for utilization of laboratory instruments

a) Questions related to the identification of the instrument and clear definition

Nature of the operation: customer service

Manufacturer, type and other special features of HPLC instrument components:

Column manufacturer, type and other special features:

The purpose of the measurement:

Name of the measurement method:

b) Questions about the utilization of the above mentioned instrument. Please estimate the data for your instrument in your laboratory:

\begin{tabular}{|l|l|}
\hline Number of annual working days: & \\
\hline Number of shifts: & \\
\hline Number of orders (projects) per year: & \\
\hline Number of identifications per year: & \\
\hline Duration of a measurement: & \\
\hline Details of the downtime in the last year & \\
\hline Number of failures: & \\
\hline Average repair time for a malfunction: & \\
\hline Number of failures due to holidays: & \\
\hline Number of days lost due to paid holiday: & \\
\hline Number of days lost due to medical reasons (sickness): & \\
\hline Number of days lost due to lack of material: & \\
\hline Number of days lost due to vacant operator position: & \\
\hline Number of days lost due to shortage of orders: & \\
\hline Number of days lost due to infrastructure shortage (power & \\
\hline Number of days lost due to other reasons *: & \\
\hline
\end{tabular}

Thanking you for your kind contribution, and looking forward to continuing collaboration on this project! Source: authors' construction (2019) 